\title{
Characterization of linagliptin using analytical techniques
}

\author{
Amanda Thomas Barden ${ }^{\mathrm{a}, *}$, Rita Elena de Abreu Engel ${ }^{\mathrm{a}}$, Sarah Chagas Campanharo ${ }^{\mathrm{a}}$, Nadia Maria \\ Volpato $^{a}$, Elfrides Eva Scherman Schapoval ${ }^{\mathrm{a}}$
}

${ }^{a}$ Faculdade de Farmácia, Universidade Federal do Rio Grande do Sul, Porto Alegre - RS, Brasil

Corresponding author e-mail: amandatbarden@gmail.com

\begin{abstract}
Linagliptin (LGT) is a member of the class of gliptins that inhibit the enzyme dipeptidyl-peptidase-4. They are used to reduce glucose blood levels in patients with type 2 Diabetes mellitus. Due to its recent development and launching on the market, LGT has no official compendium monograph, national or international, or available registries for the qualitative determination of this drug. The objective of this work was to characterize LGT by using thermal techniques, nuclear magnetic resonance, mass and infrared spectrometry, liquid chromatography and ultraviolet spectrophotometry to be used as a chemical reference substance. The range and melting point obtained are in accordance with that described in the literature. The main groups of LGT molecule were observed in infrared spectroscopy and the molecular ion $\mathrm{m} / \mathrm{z} 473.25$ ratio was found in mass spectroscopy analysis. In UV spectroscopy, the maximum wavelength absorption of the substance in different solvents can be observed. The chromatographic methods provide selectivity for LGT and can be used to analyze it qualitatively. The proposed conditions have been successfully applied for identification and qualitative analysis of LGT as a chemical reference substance, contributing to studies of this gliptin, and to the quality control of medicines that contain it.
\end{abstract}

Keywords: linagliptin; spectrometry; chemical reference substance; liquid chromatography; nuclear magnetic resonance.

\section{Introduction}

It is essential to know the physicochemical properties of active substances in order to develop pharmaceuticals and medications (1). For this purpose, it is necessary to characterize the raw material in order to ensure the substance properties, lot by lot, including the identification of the different crystalline forms of the substance (polymorphisms) (2).

Chemical Reference Substances (CRS) are certified reference materials used to evaluate conformity of the pharmaceutical inputs and medications (3). They are substances, or in a few cases a mixture of substances, established or distributed by pharmacopeias or authorized official public institutions, with a high degree of purity and uniformity. They are intended for use in chemical and physical tests and assays, in which their properties are compared to those of the products that are being analyzed (3). The non-compendial standards of reference are substances with a high degree of purity that can be obtained through private suppliers and should be characterized in order to ensure their identity, potency and purity.

The linagliptin utilized in this study belong to the class of gliptins that act by inhibiting the dipeptylpeptidase IV (DPP-IV). When this enzyme is inhibited, the active principle prevents the destruction of the incretins (GLP1 and GIP), hormones that stimulate pancreas to produce insulin when the glucose level in the blood is high. In addition, gliptins reduce the glucagon levels in patients who do not manage to attain the ideal glucose levels by diet and exercise (4). Currently the pharmaceuticals that are part of this class are sitagliptin phosphate, vildagliptin, saxagliptin, alogliptin and linagliptin (5).

Among the thermal analyses, Differential Scanning Calorimetry (DSC) is a wellconsolidated technique to analyze substance purity (6). The method evaluates the purity of the compound using an analysis of the fusion peak obtained, applying the Van't Hoff fusion point law of depreciation, which foresees the reduction of the pure compound fusion point due to the presence of impurities (7). 
Another technique that is used to characterization of a substance is the infrared spectrophotometry. It supplies evidence of the presence of several functional groups in the organic structure due to the interaction of the molecules or atoms with electromagnetic radiation in a molecular vibration process (8). The infrared radiation corresponds to the part of the electromagnetic spectrum between the visible and microwave regions. Together with the Nuclear Magnetic Resonance (NMR) it can help identify unknown compounds $(8,9)$.

According to Hardy (10), "NMR designates the resonating interaction of the dipole moment of the magnetic nucleus $\mu$ in an external magnetic field with an electromagnetic field". This energy modifies the nucleus spin when the sample is exposed on a magnetic field to obtain the latter's magnetic moment. Since each nucleus has a different magnetic moment, it is possible to determine its kind of chemical bond (11).

Other qualitative methods that can be used to characterize substance samples are spectrophotometry in UV-Visible region and High Performance Liquid Chromatography (HPLC). The spectrophotometry in UV-Visible is a simple method much used to control the quality of pharmaceutical products due to the potential of the great majority of the pharmaceuticals for absorbing energy in these regions (12). HPLC, a very used technique for this purpose, is a type of chromatography that uses small columns, filled with specially prepared materials and a mobile phase that elute under high pressures. It is able to perform separations and quantitative analyses of many compounds present in various kinds of samples, on a time scale of a few minutes, with high resolution, efficiency and sensibility $(12,13)$.

In recent years, analyses by Ultra Performance Liquid Chromatography with ultraviolet and mass spectrometry detection (UPLC-UV/MS) has been proposed as a strategy to shorten the time of analysis, collecting both non fragmented and fragmented ions, which may be consecutively utilized to quantify and inform about the ion fragments $(14,15)$. MS analysis simultaneously supplies measures of exact mass and information regarding fragmentation by collecting data, using alternative low and high-energy parallel collision to acquire the spectrum.

Considering all the commented techniques, the objective of this study was to identify and characterize linagliptin CRS performing thermal analysis as fusion point and Differential Exploratory Calorimetry (DSC), infrared spectroscopy (IR), hydrogen and carbon NMR, UV/Visible spectrophotometry, HPLC-UV and UPLC with mass detection.

\section{Experimental}

\section{Linagliptin samples}

The linagliptin (CRS) used as reference was acquired from Sequoia Research Products (United Kingdom) with a stated content of $99.24 \%$, control number 12030114271, as specified in the analysis certificate.

\section{Equipments}

The equipments used in this study were Mettler Toledo, model FP 90 for fusion point analysis, Koffler equipment, Wagner \& Muniz brand for melting range, Mettler Toledo equipment, model DSC1 with heat flow, infrared spectroscopy (Perkin Elmer equipment, model Spectrum BXII), hydrogen and carbon nuclear magnetic resonance (Varian equipment, model VNMRS-300 with 300 MHz), UV/VIS spectrophotometer (Shimadzu equipment, model UV1601 PC), high performance liquid chromatographer (Shimadzu equipment, model CBM 20A) and ultra perfomance liquid chromatographer (UPLC equipment Waters ${ }^{\circledR}$ Acquity coupled to Micdromass Q-TOF micro mass spectrometer).

\section{Melting Point}

The identification of the melting point was performed by capillary method in a Mettler Toledo equipment previously calibrated. A LGT CRS sample was packed in a capillary 
tube (1 mm - diameter; $75 \mathrm{~mm}$ - length) that was heated at $10{ }^{\circ} \mathrm{C} /$ minute. The analysis was done in triplicate.

For determination of melting range of the LGT, a Koffler equipment was used. A small amount of sample was placed on a blade and covered with a cover slip. Upon heating, the LGT crystals began to liquefy, forming droplets that were observed under the microscope. Within seconds, the sample was completely liquefied.

\section{Differential Exploratory Calorimeter}

Analyzes were carried out at in an exploratory differential calorimeter by heat flow. A $1.95 \mathrm{mg}$ LGT CRS was weighed into $40 \mu \mathrm{L}$ aluminum crucible which was sealed and subjected to analysis. The initial studies were performed in a heating ramp of $10{ }^{\circ} \mathrm{C} /$ minute, with a temperature range of 30 to $300{ }^{\circ} \mathrm{C}$ and flow of $\mathrm{N}_{2}$ of $50 \mathrm{~mL} / \mathrm{min}$.

\section{Infrared Spectrophotometer}

A small amount of the LGT SQR sample was placed at the specific site of the equipment and the reading performed, since this model of equipment does not require preparation of $\mathrm{KBr}$ pellets.

\section{Nuclear Magnetic Resonance}

The basic structural analysis by ${ }^{1} \mathrm{H}$ and ${ }^{13} \mathrm{C}$ NMR it were made in a Varian apparatus using deuterated dimethylsulfoxide (DMSOd6) as solvent.

\section{Linagliptin characterization by UV, HPLC and} UPLC

Four solvents (acetonitrile (ACN), water, ethanol and methanol) were chosen for this characterization, by analyzing LGT by scanning the 200 to $400 \mathrm{~nm}$ range. The analyses were performed in quartz cuvettes with $10 \mathrm{~mm}$ optical path.
The chromatograms were obtained in a high performance liquid chromatograph, with an injection of $40 \mu \mathrm{L}$ of the solutions in an Agilent ${ }^{\circledR}$ Zorbax C8 column (150 mm x $4.6 \mathrm{~mm}$ $\mathrm{x} 5 \mu \mathrm{m}$ ) with the oven temperature at $30^{\circ} \mathrm{C}$ and mobile phase consisting of water with the addition of $1.0 \%$ triethylamine (TEA) ( $\mathrm{pH} 4.5$, adjusted with orthophosphoric acid): ACN $(80: 20, \mathrm{v} / \mathrm{v})$.

For UPLC method, the mobile phase employed was formic acid $0.1 \%(\mathrm{pH} 3.5$ adjusted with ammonium hydroxide) and methanol $(50: 50, \mathrm{v} / \mathrm{v})$, oven temperature $30^{\circ} \mathrm{C}$, $0.2 \mathrm{~mL} / \mathrm{min}$ flow and injection volume $2 \mu \mathrm{L}$. The run time was 4 minutes in an Agilent ${ }^{\circledR} \mathrm{C} 18$ Eclipse Plus RRHD column (50 mm x $2.1 \mathrm{~mm}$ $\mathrm{x} 1.8 \mu \mathrm{m})$. The profile of the molecular break of the analyte $(\mathrm{MM}=472.23 \mathrm{~g} / \mathrm{mol})$ was performed using the positive MS/MS electrospray technique.

\section{Results and Discussion}

The fusion point found was $205.2{ }^{\circ} \mathrm{C}$ and the melting range observed for LGT was 202 $205^{\circ} \mathrm{C}$. Light brown liquefaction was observed, formed between the slide and the laminule in the Koffler equipment, indicating sample degradation. The results found by Mettler Toledo and Koffler methods showed similar values among themselves and close to the value of $202{ }^{\circ} \mathrm{C}$ described in the literature (16). These methods can be used to help identify the LGT.

The methodology used to perform DSC analysis is described in Standard ASTM E 92803 (6). By analyzing the results of the heating curve of DSC (Figure 1), it was found that an endothermal event occurred at $60.26{ }^{\circ} \mathrm{C}$ characteristic of desolvatation, followed by another endothermal event of fusion at 203.92 ${ }^{\circ} \mathrm{C}$. Later, an exothermal event followed, with fusion enthalpy $(\Delta \mathrm{H})$ of $183.12 \mathrm{~J} / \mathrm{g}$, with degradation at $245.02{ }^{\circ} \mathrm{C}$. The value obtained for fusion is close to the $202{ }^{\circ} \mathrm{C}$ described by the literature (16). The degradation event was also observed in obtaining the melting range using the Koffler method. 


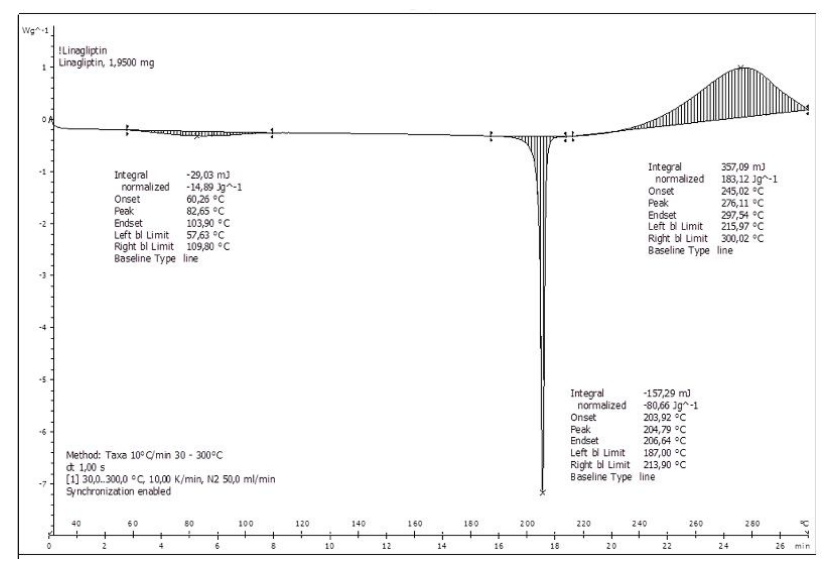

Figure 1 Heating curve of LGT CRS obtained by DSC.

Based on the information supplied by the IR spectrum of LGT (Figure 2), Table 1 was elaborated to summarize the main absorption bands obtained. The characteristic bands of LGT were identified based on the literature (8,11,17-19).

Table 1 Interpretation of the main bands of the IR spectrum of LGT CRS

\begin{tabular}{ll}
$\begin{array}{c}\text { Wave number } \\
\left(\mathbf{c m}^{-1}\right)\end{array}$ \\
\hline $\begin{array}{c}2848.81 \text { and } \\
2922.82\end{array}$
\end{tabular}

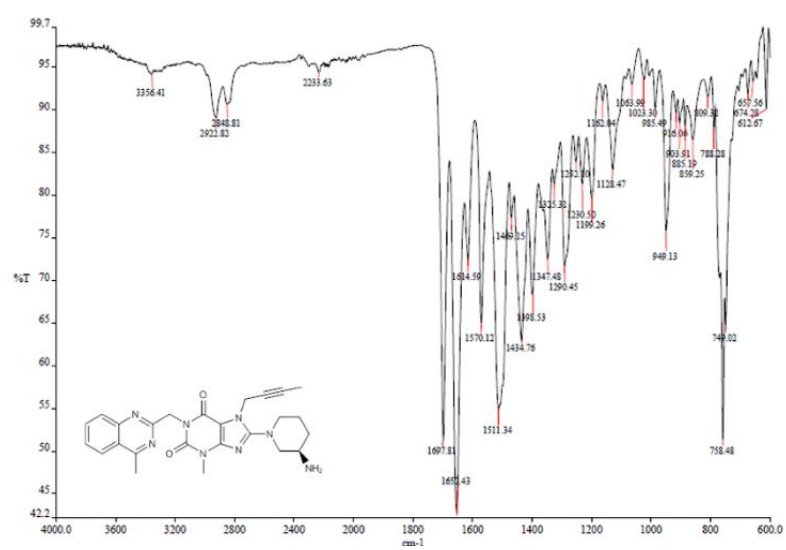

Figure 2 Spectrum in the IR region of linagliptin CRS.

The bands found correspond to the main functional clusters of LGT, confirming the identity of the sample acquired. In the analysis by $\mathrm{RMN}^{1} \mathrm{H}$ and $\mathrm{RMN}^{13} \mathrm{C}$, the resulting spectra are demonstrated in Figures 3 and 4, respectively.

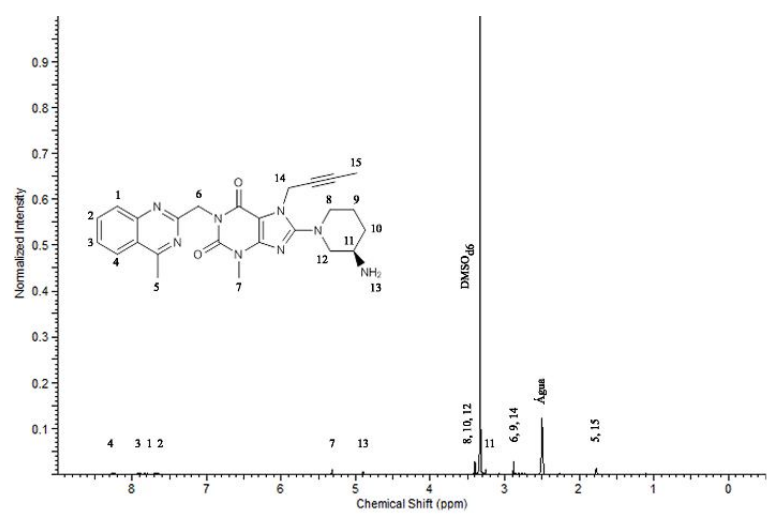

Figure 3 Spectrum of $\mathrm{RMN}^{1} \mathrm{H}$ of LGT CRS in DMSOd6 solvent at $400 \mathrm{MHz}$.

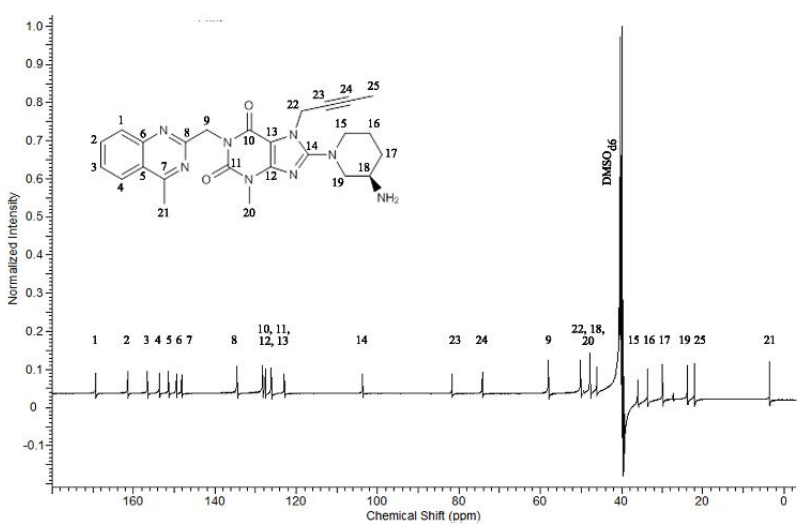

Figure 4 Spectrum of $\mathrm{RMN}^{13} \mathrm{C}$ of LGT CRS in DMSOd6 solvent at $100 \mathrm{MHz}$. 
The assignments of the spectrum of RMN ${ }^{1} \mathrm{H}$ and $\mathrm{RMN}^{13} \mathrm{C}$ of LGT CRS are shown in Tables 2 and 3, respectively. The analyses of the assignments of hydrogens and carbons were determined based on the literature $(8,11,20)$. The results obtained allowed the identification of the LGT, since the signals agree with the assignments expected for the pharmaceutical that is being analyzed.

Table 2 Assignments of $\mathrm{RMN}^{1} \mathrm{H}$ spectrum obtained by analyzing LGT CRS in DMSOd6.

\begin{tabular}{|c|c|c|c|c|}
\hline Position & $\begin{array}{c}\text { Chemical } \\
\text { Shift (ppm) }\end{array}$ & Multiplicity & $\begin{array}{l}\text { Number of } \\
\text { hydrogens }\end{array}$ & Assignment \\
\hline 5,15 & $1.75-1.79$ & Singlet & $6 \mathrm{H}$ & $\mathrm{CH}_{3}$ \\
\hline - & $2.49-2.51$ & Multiplet & - & Solvent (water) \\
\hline $6,9,14$ & $2.80-2.90$ & Multiplet & $6 \mathrm{H}$ & $\mathrm{CH}_{2}$ \\
\hline 11 & 3.26 & Singlet & $1 \mathrm{H}$ & $\mathrm{CH}$ \\
\hline- & $3.32-3.34$ & Multiplet & - & $\begin{array}{l}\text { Solvent } \\
\left(\text { DMSO }_{\mathrm{d} 6}\right)\end{array}$ \\
\hline $\begin{array}{l}8,10 \\
12\end{array}$ & $3.35-3.36$ & Multiplet & $6 \mathrm{H}$ & $\mathrm{CH}_{2}$ \\
\hline 13 & $4.88-4.91$ & Duplet & $2 \mathrm{H}$ & $\mathrm{NH}_{2}$ \\
\hline 7 & 5.32 & Singlet & $3 \mathrm{H}$ & $\mathrm{CH}_{3}$ \\
\hline 2 & $7.65-7.70$ & Triplet & $1 \mathrm{H}$ & $\begin{array}{c}\mathrm{CH} \text { aromatic } \\
\text { ring }\end{array}$ \\
\hline 1 & $7.79-7.83$ & Duplet & $1 \mathrm{H}$ & $\begin{array}{l}\mathrm{CH} \text { aromatic } \\
\text { ring }\end{array}$ \\
\hline 3 & $7.88-7.94$ & Triplet & $1 \mathrm{H}$ & $\begin{array}{l}\mathrm{CH} \text { aromatic } \\
\text { ring }\end{array}$ \\
\hline 4 & $8.23-8.27$ & Duplet & $1 \mathrm{H}$ & $\begin{array}{l}\mathrm{CH} \text { aromatic } \\
\text { ring }\end{array}$ \\
\hline
\end{tabular}

Table 3 Assignments of the spectrum of $\mathrm{RMN}^{13} \mathrm{C}$ obtained by analysis of LGT CRS in DMSOd6.

\begin{tabular}{ccc}
\hline Position & Chemical shift $(\mathrm{ppm})$ & Interpretation \\
\hline 21 & 3.57 & $\mathrm{CH}_{3}$ \\
\hline 25 & 22.06 & $\mathrm{CH}_{3}$ \\
\hline 15.16 .17 .19 & $22.06-35.98$ & $4\left(\mathrm{CH}_{2}\right)$ \\
\hline- & $39.26-40.61$ & Solvent $\left(\mathrm{dmsO}_{\mathrm{d}}\right)$ \\
\hline 20 & 46.04 & $\mathrm{~N}-\mathrm{CH}_{3}$ \\
\hline 22.18 & $47.76-50.07$ & $\mathrm{~N}-\mathrm{CH}_{2}$ \\
\hline 9 & 57.99 & $\mathrm{~N}-\mathrm{CH}_{2}$ \\
\hline 23.24 & $74.25-81.62$ & $\mathrm{C} \equiv \mathrm{C}$ \\
\hline 14 & 103.69 & $3 \mathrm{~N}-\mathrm{C}$ \\
\hline 12.13 & $122.95-126.18$ & $-\mathrm{C}=\mathrm{C}-\mathrm{N}$ \\
\hline 10.11 & $127.60-128.33$ & $2(\mathrm{CON})$ \\
\hline 8 & 134.54 & $1 \mathrm{C}$ aromatic \\
\hline 1.2 .3 .4 .5 .6 & $148.19-169.31$ & $6 \mathrm{C}$ aromatic \\
\hline
\end{tabular}

After the LGT was identified, it was characterized by UV absorption spectrophotometry. The UV spectra obtained in the different solvents are shown in Figure 5.

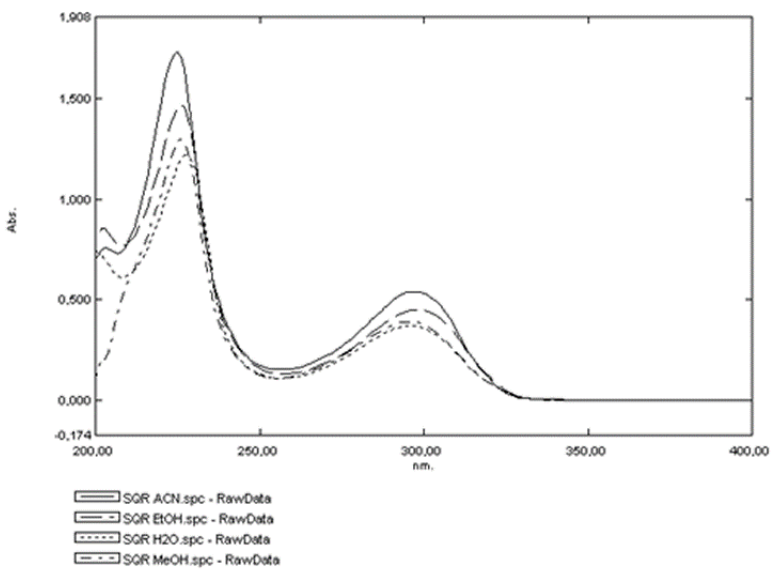

Figure 5 Comparison of the UV spectra of LGT CRS in different solvents at a concentration of $10 \mu \mathrm{g} / \mathrm{mL}$.

According to the spectra, two maximums of LGT absorption can be observed around 226 $\mathrm{nm}$ and $293 \mathrm{~nm}$. Methanol is the solvent used to extract LGT from the pharmaceutical form in papers published in the literature $(21,22,23)$. However, the greatest absorptivity was obtained in the two maximum wavelengths for the solvents acetonitrile and ethanol.

LGT was also evaluated using chromatographic methods aiming to look at substance purity. Figure 6 shows the chromatogram by HPLC of the pharmaceutical with a retention time of 6.47 minutes at a concentration of $10 \mu \mathrm{g} / \mathrm{mL}$. The suitability parameters of the system were obtained and the values found were k' equal to 4.04; tail factor equal to 1.23; theoretical plates equal to 4842. Peak purity can be evaluated using LC-Solution software and the results obtained indicate that the method was selective for the substance tested.

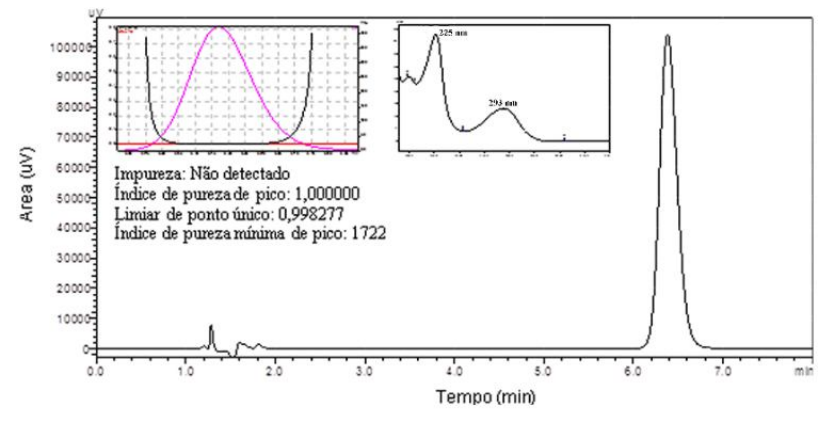

Figure 6. Linagliptin chromatogram with retention time in 6.47 minutes. Peak purity and UV spectrum were evaluated. Suitability parameters of the system: $\mathrm{k}^{\prime}=4.04$, tail factor $=1.23$, theoretical plates $=4842$. 
The qualitative method by the UPLC proposed supplied a retention time of 1.36 minutes, and was also selective for the LGT substance. The chromatogram obtained, as well as the UV spectrums acquired by the diode array detector UV spectrum are shown in Figure 7.

As in the method by HPLC, the separation was efficient for LGT. The qualitative method developed also allowed the analysis of the mass spectrum of the analyte. The result is in figure 7.
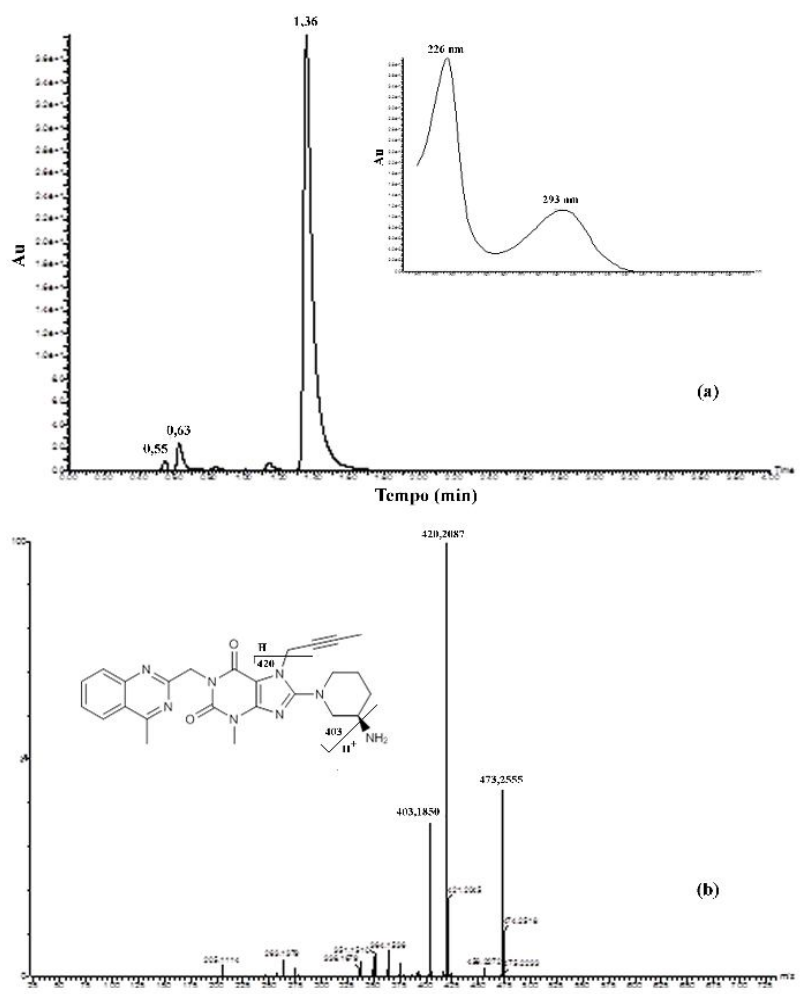

Figure 7 (a) LGT chromatogram at a concentration of $20 \mu \mathrm{g} / \mathrm{mL}$ with respective UV spectrum in the method using UPLC; (b) Mass spectrum of LGT and majority breakdown profile.

The mass spectrum confirms the presence of LGT in the solution by recording the molecular ion $\mathrm{m} / \mathrm{z} 473.2555$ ratio according to what is expected for LGT. The method proposed proves effective to characterize the LGT. The majority breakdown profile indicates molecular ions with a ratio of $\mathrm{m} / \mathrm{z} 420.2087$ and $\mathrm{m} / \mathrm{z} 403.1850$ which can be explained by the loss of the 2,3-butino and primary amine clusters, respectively.

\section{Conclusions}

The thermal behavior of LGT CRS per fusion point, melting range and DSC was important to identify and evaluate the sample purity, presenting fusion point and melting range close to the value described in the literature.

The characteristic absorption bands of LGT obtained by IR analysis supplied information needed to identify the sample. Additionally, the data obtained in the spectrum of $\mathrm{RMN}^{1} \mathrm{H}$ and $\mathrm{RMN}^{13} \mathrm{C}$ provided the characteristic signals of hydrogens and carbons of the molecule. Furthermore, the results obtained from mass spectrum provided the mass load ratio attributed to LGT, besides the major degradation profile of the molecule. The UV spectrophotometric method allowed obtaining the maximums and minimums of absorption of LGT. The chromatographic methods by HPLC and UPLC enabled the identification of LGT through the retention times and UV spectrum obtained. The identity of the material acquired has been confirmed and it is possible to affirm that this chemical reference substance can be used in later qualitative and quantitative studies.

Therefore, the proposed conditions were successfully applied for identification and qualitative analysis of LGT as a chemical reference substance, contributing to studies of this gliptin, and to the quality control of medicines that contain it.

\section{Acknowledgements}

The authors of this paper thank CNPq and Capes for financial support and the Prati Donaduzzi pharmaceutical industry and Instituto de Química at UFRGS for making the equipment available.

\section{Declaration of Interest}

The authors declare no declarations of interest. 


\section{References}

1. Rodrigues, P.O., Cardoso, T.F.M., Silva, M.A.S., Matos, J.R. Aplicação de Técnicas Termoanalíticas na Caracterização, Determinação da Pureza e Cinética de Degradação da Zidovudina (AZT). Acta Farm. Bonaerense. 2005; 24(3): 383-387.

2. Barreiro, E.J., Fraga, C.A.M. Química Medicinal: as bases moleculares da ação dos fármacos. $1^{\mathrm{a}}$. Edição, Porto Alegre: Artmed Editora, 2001.

3. Brasil. Farmacopeia Brasileira, volume 2 / Agência Nacional de Vigilância Sanitária. Brasília: Anvisa, 2010; 546p.

4. Scheen, A.J. Diabetes Metab, 2012, 38, 89.

5. Neumiller, J. J.; Setter, S. M. Clin. Ther., 2012, 34,

6. ASTM E 928, 2003. Standard Test Method for Determination of Purity by Differential Scanning Calorimetry. ASTM International, West Conshohocken, PA, 2003.

7. Van Dooren, A.A., Müller, B.W. Purity determinations of drugs with differential scanning calorimetry (DSC) - a critical review. International Journal of Pharmaceutics. 1984; 20:217-233.

8. Pavia, D.L., Lampman, G.M., Kriz, G.S. Introduction to spectroscopy: a guide for students of organic chemistry. 3rd ed. United States of America: Brooks / Cole, c2001. ca. $600 \mathrm{p}$.

9. Cienfuegos, F., Vaitsman, D. Análise Instrumental. Rio de Janeiro: Interciência. 2000; 287:41-55.

10. Hardy, E.H. NMR Methods for the Investigation of Structure and Transport. Berlin, Heidelberg: Springer Berlin Heidelberg, 2012.
11. Silverstein, R.M., Webster, F.X., Kiemle, D.J. Identificação espectrométrica de compostos orgânicos. 7. ed. Rio de Janeiro, RJ: LTC. 2007; 490 p.

12. Watson, G. D. Pharmaceutical analysis: A textbook for pharmacy students and pharmaceutical chemists. 2. Ed. London: Churchill Livingstone, 2005.

13. United States Pharmacopeia 36 ed. Rockville: United States Pharmacopeial Convention, 2013.

14. Bateman, K.P., Castro-Perez, J., Wrona, M., Shockcor, J.P., Yu, K., Oballa, R., NicollGriffith, D.A. MSE with mass defect filtering for in vitro and in vivo metabolite identification. Rapid Commun Mass Spectrom. 2007; 21(9): 1485-1496.

15. Castro-Perez, J.M., Kamphorst, J., DeGroot, J., Lafeber, F., Goshawk, J., Yu, K., Shockcor, J.P., Vreeken, R.J., Hank'Semeier, T. Comprehensive LC-MSE Lipidomic Analysis using a Shotgun Approach and Its Application to Biomarker Detection and Identification in Osteoarthritis Patients. Journal of Proteome Research. 2010; 9(5): 2377-2389.

16. Eckhardt, M., Langkopf, E., Mark, M., Tadayyon, M., Thomas, L., Nar, H., Pfrengle, W., Guth, B., Lotz, R., Sieger, P., Fuchs, H., Himmelsbach, F. 8-(3-(R)-Aminopiperidin-1yl)-7-but-2-ynyl-3-methyl-1-(4-methylquinazolin-2-ylmethyl)-3,7-dihydropurine-2,6dione (BI 1356), a Highly Potent, Selective, Long-Acting, and Orally Bioavailable DPP-4 Inhibitor for the Treatment of Type 2 Diabetes. Journal of Medicinal Chemistry. 2007; 50(26): 6450-6453.

17. Culbertson, H., Decius, J. C., Christensen,B.E. Quinazolines.XIII. A Study of the Infrared Spectra of Certain Quinazoline Derivatives. Journal of American Chemical Society. 1952; 74(19): 4834-4838.

18. Lister, J.H., Jones, R.L., Lawley, P.D., Hitchings, G.H., Elion, G.B. The Chemistry of 
Heterocyclic Compounds, Fused Pyrimidines: The Purines. Parte 2, volume 24. Editora John Wiley \& Sons, 655 p.

19. Chaves, H.K. Dissertação de mestrado: $\mathrm{O}$ efeito do substituinte no anel piperidina na reatividade de pré-catalizadores do tipo $\left[\mathrm{RuCl}_{2}\left(\mathrm{PPh}_{3}\right)_{2}\left(4-\mathrm{CH}_{2} \mathrm{X}\right.\right.$-pip)] em ROMP. 78f. Universidade de São Paulo, São Paulo, 2011.

20. Pretsch, E., Clerc, T., Seibl, J., Simon, W. Tablas para la elucidacion structural de compuestos orgânicos por metodos espectroscópicos, 2 ed. Madrid: Alhambra, 1985.

21. Badugu, L.R. A Validated RP-HPLC Method for the Determination of Linagliptin. American American Journal of PharmTech Research. 2012; 2(4): 462-470.

22. El-Bagary, R.I., Elkady, E.F., Ayoub, B.M. Liquid Chromatographic Determination of Linagliptin in Bulk, in Plasma and in its Pharmaceutical Preparation. International Journal of Biomedical Science. 2012; 8(3): 209-14.

23. Archana, M., Sriram, N., Gayasuddin, M. Method development and validation of RPHPLC method for determination of new antidiabetic agent linagliptin in bulk and in pharmaceutical formulation. International Journal of Mechanical Engineering and Computer Applications. 2013; 3(1): 1-5. 